\title{
Novel binding partners of Ldb1 are required for haematopoietic development
}

\author{
Natalia Meier ${ }^{1}$, Sanja Krpic ${ }^{1}$, Patrick Rodriguez ${ }^{1}$, John Strouboulis ${ }^{1}$, Maria Monti ${ }^{2}$, Jeroen Krijgsveld ${ }^{2}$, \\ Martin Gering ${ }^{3}$, Roger Patient ${ }^{3}$, Arnd Hostert ${ }^{1}$ and Frank Grosveld ${ }^{1}$,*
}

Ldb1, a ubiquitously expressed LIM domain binding protein, is essential in a number of tissues during development. It interacts with Gata1, Tal1, E2A and Lmo2 to form a transcription factor complex regulating late erythroid genes. We identify a number of novel Ldb1 interacting proteins in erythroleukaemic cells, in particular the repressor protein Eto-2 (and its family member Mtgr1), the cyclin-dependent kinase Cdk9, and the bridging factor Lmo4. MO-mediated knockdowns in zebrafish show these factors to be essential for definitive haematopoiesis. In accordance with the zebrafish results these factors are coexpressed in prehaematopoietic cells of the early mouse embryo, although we originally identified the complex in late erythroid cells. Based on the change in subcellullar localisation of Eto-2 we postulate that it plays a central role in the transition from the migration and expansion phase of the prehaematopoietic cells to the establishment of definitive haematopoietic stem cells.

KEY WORDS: Ldb1, Transcription factor complexes, Haematopoietic stem cells, Haematopoiesis

\section{INTRODUCTION}

Erythrocytes are derived from the haematopoietic stem cell (HSC) (Durand and Dzierzak, 2005). From approximately E8.5 to E10.5 in the mouse, definitive HSCs are derived from the aorta-gonado-mesonephros region (AGM) (Medvinsky and Dzierzak, 1996; Yoder et al., 1997; de Bruijn et al., 2000; Cumano et al., 2001). Recently the placenta has been identified as a further source of adult HSCs (Gekas et al., 2005; Ottersbach and Dzierzak, 2005). At E11 the mouse fetal liver becomes the main organ of haematopoiesis, later replaced by the bone marrow.

HSC differentiation involves coordinated changes in transcription, often by functionally conserved genes such as Gata2, Tal1, Lmo2, Gata1 and Runxl/Aml1 (Cantor and Orkin, 2001).

Often the binding sites for transcription factor complexes are located at great distance from the genes that they control. In the human and mouse $\beta$-globin locus, the interacting binding sites and genes are spread over a distance of $100 \mathrm{~kb}$. A three-dimensional structure resulting from long-range interactions, the Active Chromatin Hub $(\mathrm{ACH})$, has recently been demonstrated (Tolhuis et al., 2002; Palstra et al., 2003; Patrinos et al., 2004). We anticipate that (novel) classes of proteins will mediate such 3D interactions of distal regulatory elements. An example of such a protein is Chip/Ldb1 (Morcillo et al., 1997), a protein that can interact with the insulator protein $\mathrm{Su}(\mathrm{Hw})$ (Torigoi et al., 2000). Initially isolated in a screen for proteins that bind LIM domains (Agulnick et al., 1996), orthologues of Ldb1 have now been identified in a range of other species. Ldb1 is a ubiquitously expressed nuclear protein that does not bind DNA but appears to participate in transcriptional control by acting as a co-factor for other proteins. It is part of a

\footnotetext{
${ }^{1}$ Department of Cell Biology and Genetics, Erasmus MC, PO Box 2040, 3000 CA, Rotterdam, The Netherlands. ${ }^{2}$ Department of Biomolecular Mass Spectrometry, Bijvoet Center for Biomolecular Research and Utrecht Institute for Pharmaceutical Sciences, Utrecht University, Sorbonnelaan 16, 3584CA, Utrecht, The Netherlands. ${ }^{3} \mathrm{MRC}$ Molecular Haematology Unit, The Weatherall Institute of Molecular Medicine, University of Oxford, Oxford OX3 9DS, UK.
}

*Author for correspondence (e-mail: f.grosveld@erasmusmc.nl) protein complex in murine erythroid cells composed of the haematopoietic transcription factors Lmo2, Tal1, Gata1 and E2A (Tcfe2a - Mouse Genome Informatics) (Wadman et al., 1997) binding to a GATA-E box motif. This complex binds to the locus control region and $\beta$-globin promoter of murine erythroleukemic (MEL, C88) cells (Brand et al., 2004), to the erythroid specific glycophorin A (Gypa) promoter (Lahlil et al., 2004), and to multiple sites in the $\alpha$-globin locus during erythroid differentiation (Anguita et al., 2004).

Consistent with its interaction with a broad range of transcription factors involved in development, the $L d b l$ knockout mouse dies between E9.5 and E10.5 from a series of developmental defects, including absence of haematopoieisis (Mukhopadhyay et al., 2003) (A.H., unpublished). The latter partly resembles the knockout phenotypes of the haematopoietic transcription factors Lmo2 and Tal1 (Warren et al., 1994; Robb et al., 1995; Shivdasani et al., 1995).

In order to understand the role of Ldb1 in erythroid transcriptional interactions, we performed a biochemical screen to identify its binding partners. Using in vivo biotinylation (de Boer et al., 2003; Rodriguez et al., 2005) we describe a number of novel partners. We show that Ldb1 forms complexes that change composition during C88 cell differentiation, and that these complexes are bound to the target genes in vivo. We show that Ldb1 and its binding partners are co-expressed at early stages of development of the murine haematopoietic system, and that the novel erythroid binding partners are required for development of the definitive but not the primitive haematopoetic system of zebrafish embryos.

\section{MATERIALS AND METHODS}

\section{Ldb1 cDNA and bio-Ldb1 construct cloning}

Ldb1 cDNA was cloned from D14.5 fetal liver RNA (Trizol, Life Technologies) by RT-PCR (SuperScriptII Reverse transcriptase, Invitrogen; Pfu Polymerase, Promega) into the EcoRI site of pBluescript (pBS) (construct AH-3).

ATG-less Ldb1 cDNA was amplified and cloned between the BamHI and NotI sites of pBS. The bio-tag was cloned directly in front of the ATG-less cDNA. Tagged cDNA was isolated as a Xhol-NotI fragment and cloned into the SalI and NotI sites of pEV-Neo (de Boer et al., 2003) to give construct pEV-Neo-bio-Ldb1. 


\section{MEL cell transfection and culture}

C88 cells were cultured and induced for differentiation with DMSO as previously described (Antoniou, 1991). C88BirA cells (Rodriguez et al., 2005) were transfected by electroporation with ScaI-linearised pEV-NeobioLdb1, cultured in 96-well plates containing medium with $1 \mu \mathrm{g} / \mathrm{ml}$ puromycin and $0.8 \mathrm{mg} / \mathrm{ml}$ neomycin to select single clones (de Boer et al., 2003; Rodriguez et al., 2005).

\section{Nuclear extract preparation}

Small-scale nuclear extract preparation of C 88 cell cultures $(30-50 \mathrm{ml})$ and nuclear extracts of larger cultures $(5.5-9 \mathrm{~L})$ were prepared as described by de Boer et al. (de Boer et al., 2003).

\section{Strepatavidin pulldown and mass spectrometry}

Strepatavidin-coated Dynabeads M-280 (Dynal) were blocked for 1 hour with chicken serum albumin/PBS $(200 \mathrm{ng} / \mu \mathrm{l})$. The salt and detergent concentrations of nuclear extract samples of 5-6 mg from induced C88BirA/bio-Ldb1 cells or $15 \mathrm{mg}$ from noninduced C88BirA/bioLdb1 cells were adjusted to $200 \mathrm{mM} \mathrm{KCl}$ and $0.3 \%$ NP40 with $10 \mathrm{mM}$ $\mathrm{KCl}$ buffer $\left(10 \mathrm{mM} \mathrm{KCl}, 10 \mathrm{mM}\right.$ HEPES-KOH, $1.5 \mathrm{mM} \mathrm{MgCl}_{2}, 25 \%$ glycerol, $0.75 \%$ NP40, $2 \mathrm{mM}$ PMSF) prior to overnight incubation with blocked beads at $4{ }^{\circ} \mathrm{C}$. The beads were washed for 5 minutes six times in washing solution (150/200 mM KCl, $10 \mathrm{mM}$ HEPES-KOH pH 7.9, 1.5 $\mathrm{mM} \mathrm{MgCl} 2,0.2 \mathrm{mM}$ EDTA, 0.3\% NP40, $0.2 \mathrm{mM} \mathrm{PMSF)} \mathrm{at} \mathrm{room}$ temperature. Pulled down proteins were processed and analysed by mass spectrometry (LC-MSMS, MS) as described (Rodriguez et al., 2005).

\section{Immunoprecipitations and western blot analysis}

Immunoprecipitations and western blot analysis were performed as previously described (Rodriguez et al., 2005). Bio-Ldb1 was detected using a 1/10,000 dilution of Streptavidin-Horseraddish Peroxidase (HRP) conjugate (NEN).

\section{Antibodies}

Monoclonal rat antibodies against Mtgr1 and Lyl1 were produced by Absea The antibody against E2-2 was obtained from Abcam (ab2233), and all others were from Santa Cruz Biotechnology: $\alpha$-Ldb1 (sc-11198), $\alpha$-Lmo2 (sc-10499), $\alpha$-Lmo4 (sc-11121, sc-22833), $\alpha$-Eto-2 (sc-9741), $\alpha$-Runx1 (sc8563), $\alpha$-Cdk9 (sc-484), $\alpha$-HEB (sc-357), $\alpha$-E2A (sc-349), $\alpha$-Gata1-N6 (sc$265), \alpha$-HDAC1 (sc-7872), $\alpha$-NMP 238 (sc-15259). The antibody against NMP 238 was used as a loading control for the IP experiments, because it showed no change after induction.

\section{Chromatin immunoprecipitations}

Fixation, lysis of cells and sonication of chromatin were performed as previously described (Rodriguez et al., 2005). Primers for realtime PCR were as described (Rodriguez et al., 2005). Primers for the Gata1 hypersensitive site (HS) and negative control sequences were:

Gata1 HS-3.5 Reverse primer: 5'-CCGGGTTGAAGCGTCTTCT-3'

Gata1 HS-3.5 Forward primer: 5'-TCAGGGAAGGATCCAAGGAA-3'

Gata1 Negrev: 5'-TGCCGCTTGCCTTTGTAAG-3'

Gata1 Negfor: 5'-CACTAGCAGCTGGGTGGGTTA-3'

\section{Zebrafish maintenance and morpholino injections}

Wild-type zebrafish were kept and staged according to Westerfield (Westerfield, 1993). ATG morpholinos (MO) (Gene-Tools) and corresponding mismatch MOs were derived from the genebank cDNA of ldb1 (NM_131313, 5'-GCCCACGTCTCGGTCCAGCATGGTG-3'), tcf4 (NM_131259, 5'-AGCTGCGGCATTTTTCCCGAGGAGC-3'), cdk9 (BC055634, 5'-CGACGCCATCGTAGTATTTGGACAT-3', control mismatch MO 5'-CGAgGaCATCGTAcTATTTaGAgAT-3'), lmo4 (NM_177984， 5'-AGCTTTCCACACGACTGTTCACCAT-3'， control mismatch MO 5'-AGgTTTgCACACcACTGTTgACgAT-3'), mtgr1 (XM_695328 5'-CTCTTAAAAGCGTGAAAGACCGCAT-3', control mismatch MO 5'-CTgTTAAAAcCGTcAAAGAgCGgAT-3'), eto-2 (EST AF164710 5'-AACATGACGGTTGGAACTCTGGTT-3', control mismatch MO 5'-AAgATcACGGTTcGAACTgTGcTT-3').
All MOs were dissolved in water to a concentration of $1 \mathrm{mM}$ and injected at three doses $(0.1 \mathrm{nl}, 0.5 \mathrm{nl}$ and $1.2 \mathrm{nl})$ into zebrafish embryos at the two- to eight-cell stage. As an injection control, rhodamin-dextrane or phenol red were added to a concentration of $10 \% \mathrm{vol} / \mathrm{vol}$ before use.

\section{Whole mount in situ hybridisation}

Digoxigenin-UTP (Roche) labelled antisense and sense RNA probes against the zebrafish orthologues of hemoglobin beta embryonic-1 $(\beta E 1)$ (Quinkertz et al., 1999) and runxl (M. Gering) were synthesized from linearised plasmids using T3 and T7 RNA polymerases. In situ hybridisation was performed as described previously (Jowett and Yan, 1996). To remove pigmentation, embryos older than 32 hours postfertilisation (hpf) were treated with $5 \% \mathrm{H}_{2} \mathrm{O}_{2} / \mathrm{PBS}$ for 2-3 hours prior to in situ hybridisation.

Probes were detected by incubation with alkaline phosphatase coupled anti-Digoxigenin antibody (Roche) and colour reaction with Fast Red (Roche) for $\beta E 1$ and BM Purple (Roche) for runxl.

\section{Immunohistochemistry}

E9.5 FVB mouse embryos were fixed in $2 \%$ paraformaldehyde/PBS for 2 hours at room temperature. After overnight equilibration in $20 \%$ Sucrose/PBS at $4{ }^{\circ} \mathrm{C}$, embryos were orientated and quick frozen in Tissue Tek (Sakura Finetek).

Immunohistochemistry was essentially carried out as previously described (de Bruijn et al., 2002). All animal experiments were carried out according to the Dutch Welfare of Animals Act.

\section{RESULTS \\ Generation of bio-Ldb1 cells}

In order to identify Ldb1 interacting partners, C88BirA MEL cells expressing the Escherichia coli BirA protein-biotin ligase (de Boer et al., 2003) were stably transfected with pEV-Neo-bio-Ldb1 (Fig. 1A).

A total of $16 \mathrm{C} 88 \mathrm{BIR} / \mathrm{bioLdb} 1$ clones were isolated and induced to differentiate with DMSO. Nuclear extracts were tested for presence of the fusion protein using an $\alpha$-Ldb1 antibody and streptavidin-HRP (Fig. 1B). Clone \#3F4 was chosen because it expresses low levels of bio-Ldb1 (Fig. 1C) in the uninduced state. This allowed us to compare Ldb1 complexes before and after terminal differentiation.

\section{Identification of Ldb1 interaction partners}

Nuclear extracts prepared from noninduced and induced \#3F4 cells and untransfected C88 cells were incubated with streptavidin-coated paramagnetic beads, and separated by polyacrylamide gel electrophoresis (PAGE) (de Boer et al., 2003; Rodriguez et al., 2005) (Fig. 1D). Proteins were trypsin digested, eluted and analysed by mass spectrometry (LC-MSMS). Table 1 shows the pulled down proteins when washed with $150 \mathrm{mM}$ and $200 \mathrm{mM} \mathrm{KCl}$. The pattern of background proteins was similar to that observed for Gata1 (de Boer et al., 2003; Rodriguez et al., 2005) and other transcription factors (H. Braun, J. Demmers and J. Philipsen, personal communication).

The screen was validated by the fact that known Ldb1 partners (Lmo2, Tal1, Gata1 and E2A) (Wadman et al., 1997) were readily identified. We also found three proteins of the Ssdp family, members of which interact with Ldb1 in HeLa cells and in Drososphila (Chen et al., 2002; van Meyel et al., 2003; Nishioka et al., 2005). These Ssdp interactions were not analysed further. In addition, a number of novel (potential) interaction partners of different functional classes were found, including transcription (co-)factors, cell-cycle proteins, chromatin remodelling and DNA repair proteins. Some of the previously identified binding partners of Ldb1 (Tal1, E2A), the basic helix-loop-helix (bHLH) proteins HEB (Tcf12 - Mouse Genome Informatics), E2-2 (Tcf4 - Mouse Genome Informatics), 
A

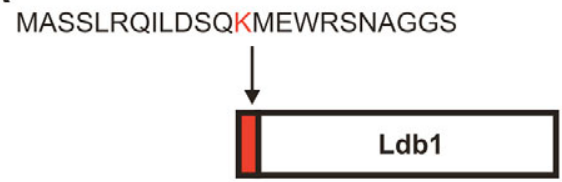

B

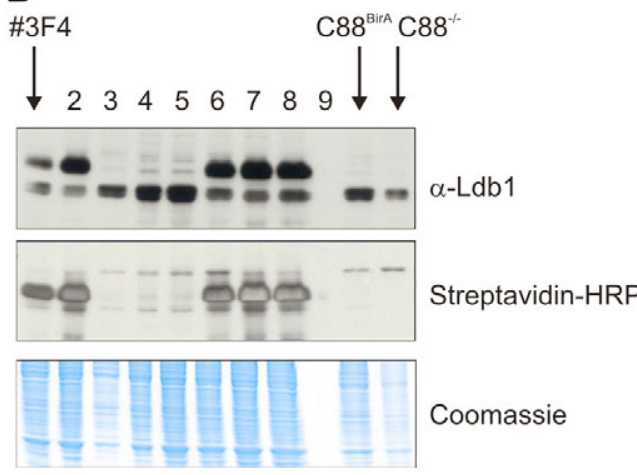

C

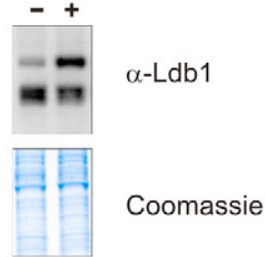

D

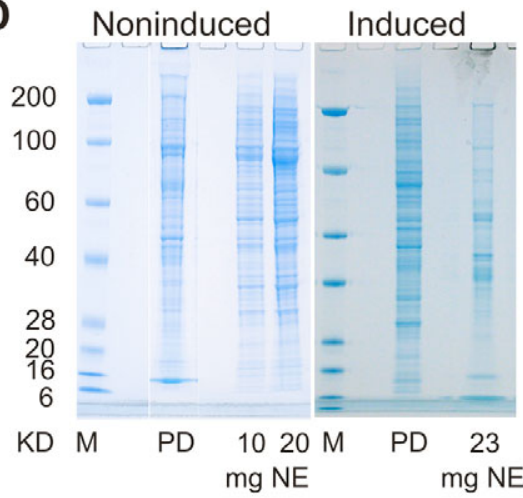

Fig. 1. Ldb1 biotinylation and streptavidin pulldown. (A) Schematic representation of bio-Ldb1. The 23 amino acid sequence recognised by BirA and a triple haemagglutinin tag are fused in tandem to the amino-terminal end of the ATG-less Ldb-cDNA. (B) Expression of $L d b 1$ and bioLdb1 in nuclear extracts of induced C88BirA/bio-Ldb1, C88-/BirA and C88 ${ }^{-1-}$ cells. Eight of 16 transfectants are shown. Three clones (lanes 3-5) did not express bio-Ldb1, lane 9 not loaded. Clone \#3F4 was chosen for further experiments. Lanes on the right are C88-/BirA and C88 ${ }^{-/-}$controls. (C) $L d b 1$ and bio-Ldb1 expression in equal amounts (see Coomassie stained gel) of nuclear extracts of noninduced (-) and induced (+) \#3F4 cells. Expression of endogenous $L d b 1$ is reduced in induced cells. (D) PAGE of proteins bound to bio-Ldb1. Pulldowns of noninduced and induced cell extracts washed at lower stringency conditions are shown. PD, pulled down proteins; NE, untreated nuclear extract.

Lyl1 and the novel interacting protein Eto-2 (Cbfa2t3h - Mouse Genome Informatics) were detected in all three analyses. Eto-2, an orthologue of the D. melanogaster gene nervy, was the most abundant protein in two of the three LC-MSMS outputs. Mtgr1 (Cbfa2t2 - Mouse Genome Informatics), another member of the ETO protein family, was also identified by MS analysis of noninduced and induced cell extracts. The known partner Lmo2 was present in extracts from noninduced and induced cells (Fig. 2), whereas Lmo4, Gata1 and Runx1 were present in the MS analyses of induced cells only, although it should be noted that Gata1 may have been absent due to the fact that only very few Gata1 peptides are detectable in our MS analyses (Rodriguez et al., 2005). In contrast to the proteins mentioned above, the cell-cycle protein Cdk9 was only found in nuclear extracts of noninduced cells. Proteins of different chromatin remodelling complexes were also identified only in induced cell extracts, for example Hdac1 (see Fig. S1B in the supplementary material), but these have as yet not been investigated in detail.

Western blots of equal amounts of nuclear extracts of noninduced and induced $\mathrm{C} 88$ cells showed that the levels of all binding partners except for the newly identified interacting proteins Eto-2, Cdk9 and Lmo4, did not change significantly (Fig. 2, input lanes) in normal untransfected cells and bio-Ldb1 cells. Levels of Lmo4 and Cdk9 increased with induction, whereas there was considerably less Eto2 in induced extracts (Fig. 2A, input Lmo4, Cdk9 and Eto-2 panels). Interestingly, the much less abundant $55 \mathrm{kD}$ isoform of Cdk9 (Shore et al., 2003) is upregulated with induction, while the $41 \mathrm{kD}$ isoform of Cdk9 decreases in untransfected MEL cells, and is present at the same levels in noninduced and induced bio-Ldb1 extracts (Fig. 2, input Cdk9 panels); this phenomenon is also seen in differentiating macrophages (Liu and Herrmann, 2005).

\section{Identification of different complexes}

To confirm the interactions found in the MS analysis, immunoprecipitations of equal amounts of nuclear extracts from induced and noninduced C88 cells (Fig. 2) were performed with an $\alpha$-Ldb1 antibody. Immunoprecipitations carried out on normal C88 cells and bio-Ldb1 transfected cells showed essentially the same results. The $\alpha$-Ldb1 antibody depleted the extracts of noninduced cells almost completely of Ldb1 (Fig. 2A,B). Lmo2, Tal1, the two E2A isoforms E12 and E47, HEB and Gata1, precipitated equally with Ldb1 before and after induction (not shown). The only difference we observed between the bio-Ldb1 transfected cells and untransfected cells was a small change in the ratio of expression of E12 and E47 (Fig. 2A,B, E2A panels). Consistent with its lower level in induced cell extracts, less Eto-2 precipitated with Ldb1 from induced cell extracts compared with that of noninduced cells (Fig. 2A,B, Eto-2 panels). Mtgr1, the other identified Eto-family member, was also enriched to a lesser extent in induced cells (Fig. 2A,B, Mtgr1 panels). As expected, more Lmo4 precipitated with Ldb1 in induced cells compared with noninduced cells (Fig. 2A,B, Lmo4 panels), whereas the amount of coprecipitated Lmo2 did not change (not shown). These results suggest that the newly identified partner Lmo4 may play a more important role at later stages of erythroid differentiation. Most notably, the two isoforms of $\mathrm{Cdk} 9$ immunoprecipitated with Ldb1 only in noninduced cells (Fig. 2A,B, Cdk9 panels). As Cdk9 is involved in cell-cycle progression (Bettencourt-Dias et al., 2004), its interaction with Ldb1 in noninduced, proliferating C88 cells only, may link the complex containing Ldb1 and Cdk9 to the maintenance of the proliferative state. Although their level is unchanged, there was less coprecipitation of E2-2 and Lyl1 with either $\alpha$-Ldb1 (Fig. 2A,B) or $\alpha$-Eto-2 (not shown) in induced cells. 
Table 1. Proteins identified by LC-MSMS in bio-Ldb1 pulldown experiments

\begin{tabular}{lcccc}
\hline $\begin{array}{l}\text { Proteins pulled down } \\
\text { C88/BirA }\end{array}$ & $\begin{array}{c}\text { Non-induced } \\
\text { LS }\end{array}$ & $\begin{array}{c}\text { Induced 1 } \\
\text { LS }\end{array}$ & $\begin{array}{c}\text { Induced 2 } \\
\text { HS }\end{array}$ \\
\hline Transcription factors & & & & \\
\hline LIM only proteins & & & & \\
\hline Lmo2 & - & + & - & + \\
Lmo4 & - & - & + & + \\
\hline
\end{tabular}

Zinc finger proteins

\begin{tabular}{lllll}
\hline Gata1 & - & - & + & + \\
\hline Basic helix-loop-helix & & & & \\
\hline Tal1 & - & + & + & + \\
E2A & - & + & + & + \\
Lyl1 & - & + & + & + \\
HEB & - & + & + & + \\
E2-2 & - & + & + & + \\
\hline
\end{tabular}

ETO-family

\begin{tabular}{lllll}
\hline Eto-2 & - & + & + & + \\
Mtgr1 & - & + & - & + \\
\hline
\end{tabular}

Runt domain

\begin{tabular}{llllll}
\hline Runx1 & - & - & - & + & + \\
\hline
\end{tabular}

Ssdp

\begin{tabular}{lllll}
\hline Ssdp2 & - & + & + & + \\
Ssdp3 & - & + & + & + \\
RIKENCDNA1210001E11 & - & + & + & +
\end{tabular}

(Ssdp4)

Cell-cycle proteins/kinase

\begin{tabular}{llllll}
\hline Cdk9 & - & & + & - & - \\
\hline
\end{tabular}

The lower amount of identified proteins and their corresponding peptides in the lower stringency pulldown experiment of induced cells (induced 1) is due to the lower amount of input for the LC-MSMS analysis.

LS, low stringency; HS, high stringency.

In order to gain a better understanding of some of the Ldb1containing complexes, and to determine whether Ldb1 binding partners bind to Ldb1 in the absence of Eto- 2 and vice versa, we performed sequential immunoprecipitation experiments. We first depleted nuclear extracts of either Ldb1 or Eto-2 with their respective antibodies, and then incubated the supernatants with $\alpha$ Eto- 2 and $\alpha$-Ldb1 respectively (Fig. 3 and see Fig. $1 \mathrm{~A}$ in the supplementary material). Immunoprecipitations were then analysed for Ldb1 interacting proteins identified and validated in the single immunoprecipitation experiments (Fig. 3). It should be noted that we have not set out to characterise all the possible complexes that may be formed by every single Ldb1 interacting partner identified in the MS analysis, a task which is outside the scope of this paper.

As noted above, the $\alpha$-Ldb1 antibody (almost) completely depletes Ldb1 protein from the extract (Figs 2, 3, Ldb1 panels). A precipitation with $\alpha$-Eto- 2 antibody brings down high amounts of $\mathrm{Ldb} 1$, indicating that a high proportion of complexes contains both Ldb1 and Eto-2. However, $\alpha$-Eto-2 did not deplete the extract of $\mathrm{Ldb} 1$ protein, as more Ldb1 protein is precipitated with $\alpha$-Ldb1 from the $\alpha$-Eto-2 treated supernatant (Fig. 3, Ldb1 panels). Conversely, precipitation of Ldb1 with $\alpha$-Ldb1 antibody brings down large amounts of Eto-2 (Figs 2, 3, Eto-2 panels) but does not deplete Eto-2 completely from the extract, as there is more Eto-2 left in the supernatant (Fig. 3, Eto-2 panel). Thus, there are probably at least three complexes, one containing both Eto- 2 and Ldb1, one that contains Ldb1 but not Eto-2, and one that contains Eto-2 but not Ldb1 (Fig. 3B).

To investigate the binding behaviour of $\mathrm{Cdk} 9$, the only protein that does not interact with Ldb1 upon induction of differentiation, we tested the sequential immunoprecipitations for its presence. $\alpha$-Ldb1 antibody precipitated Cdk9 with a substantial amount left in the supernatant, which was not precipitable by $\alpha$-Eto- 2 antibody (Fig. $3, \mathrm{Cdk} 9$ panel). In reverse, incubation of nuclear extracts with $\alpha$-Eto2 antibody also precipitated Cdk9 only partially, the remainder also not being bound to Ldb1 (Fig. 3, Cdk9 panel). We suggest that Cdk9 requires both Ldb1 and Eto-2 for its interaction with either of the two proteins. E2-2 and Lyl1 exhibited similar interaction behaviour (Fig. 3 ), with the exception that Lyl1 is also bound to Ldb1 alone (Fig. 3B).

To test whether the Ldb1-Lmo2 interaction requires Eto-2, we first depleted Eto- 2 followed by Ldb1 immunoprecipitation and testing for Lmo2 (Fig. 3, Lmo2 panels). $\alpha$-Eto-2 brought down only some Lmo2. As all of Lmo2 is in complex with Ldb1 (Fig. 3), we conclude that there is a complex containing Lmo2-Ldb1-Eto-2, and that the remaining Lmo2 left in the supernatant after Eto- 2 depletion is bound to Ldb1, but not Eto-2. Lmo4 behaves similarly but shows an important quantitative difference. There is little Lmo4 before differentiation, but this increases several fold after induction of differentiation (Fig. 2).

The two isoforms of E2A show a different binding behaviour. Both the larger E47 and smaller E12 isoforms are precipitated equally by Ldb1, albeit incompletely. The remaining E47, but not E12, is bound by Eto-2 (Fig. 3 and see Fig. S1A in the supplementary material; E2A panels). Conversely, $\alpha$-Eto- 2 completely depletes the extracts of the E47 isoform but binds only some E12 (Fig. 3, E2A panel). Some of this remaining E12 is precipitable by Ldb1. Taking into account the Ldb-1/E2A data from above, this indicates the presence of a complex containing Ldb1/Eto-2/E47/E12, two further complexes composed of at least Eto-2/E47 or Ldb1/E12, and 'free' E12 that can participate in other complex formation.

Mtgr1 was the second member of the Eto family identified in our MS analysis. $\alpha$-Ldb1 antibody precipitates some Mtgr1, but not all, with a substantial amount left in the supernatant that is all precipitated with an $\alpha$-Eto-2 antibody (Fig. 3, Mtgr1 panel and see Fig. S1A in the supplementary material). Precipitation with $\alpha$-Eto2 antibody, however, completely depletes Mtgr 1 from the nuclear extracts, indicating that all Mtgr1 is complexed with Eto-2 (Fig. 3 and see Fig. S1A in the supplementary material; Mtgr1 panels). We conclude that there are at least two complexes containing Mtgr1: one complex containing Mtgr1/Eto-2/Ldb1, and that the Mtgr1/Ldb1 interaction requires Eto-2; a further complex containing Mtgr1/Eto2, but not Ldb1.

Tal1 also forms several complexes, which contain either Ldb1 and/or Eto-2. $\alpha$-Ldb1 antibody precipitates most, but not all Tal1 from the nuclear extract, part of the remaining Tal1 is pulled down with Eto-2 (Fig. 3, Tal1 panel). Testing first with $\alpha$-Eto-2 shows that Eto-2 brings down some but not all Tal1; some is precipitable with an $\alpha$-Ldb1 antibody (Fig. 3, Tal1 panel). This indicates that there are at least four Tal1-containing complexes: Eto-2/Tal1/Ldb1, Ldb1/Tal1, Eto-2/Tal1 and 'free' Tal1.

HEB also forms complexes that contain either Ldb1 and/or Eto2. Both $\alpha$-Ldb1 and $\alpha$-Eto-2 precipitate large amounts of HEB indicating that HEB forms complexes with Ldb1 or Eto-2, and probably a complex containing all three of these proteins. A second precipitation with either $\alpha$-Eto- 2 or $\alpha$-Ldb1 precipitates more HEB, although small amounts remain in the supernatant after this second 
immunoprecipitation (Fig. 3, HEB panel). Therefore, HEB forms at least three complexes: HEB/Ldb1, HEB/Eto-2 and 'free' HEB. When an $\alpha$-HEB immunoprecipitation is carried out, it does precipitate all the partners, including Lyl1, Cdk9 and E2-2, suggesting that it is part of a large Ldb1/Eto-2 complex (Fig. 3B), or perhaps a smaller one containing Ldb1 and Eto-2.

Finally, Gata1, a transcription factor known to participate in a multitude of complexes (Rodriguez et al., 2005), also forms separate complexes with either Eto- 2 or Ldb1. Treatment of extracts with $\alpha$ Ldb1 antibody brings down a small part of Gata1. Further precipitation with $\alpha$-Eto- 2 provides evidence of an Eto-2-Gata1 interaction separate from Ldb1 (Fig. 3, Gata1 panel, and see Fig. $\mathrm{S} 1 \mathrm{~A}$ in the supplementary material). In reverse, $\alpha$-Eto- 2 antibody indeed precipitates part of Gata1. Very little Gata1 is then precipitable with an $\alpha$-Ldb1 antibody, indicating that possibly most of the Eto-2/Gata1 complex also contains Ldb1 (Fig. 3, Gata1 panel). We conclude that Gata1 forms at least four complexes: Gata1/Ldb1, Gata1/Eto-2, Gata1/Ldb1/Eto-2 and 'free' Gata1, which is known to participate in other complexes.

Single immunoprecipitations using antibodies for the Ldb1 interacting proteins confirmed all the pairwise interactions described above (not shown).
Although it is difficult to distinguish the complexes from each other, the data strongly suggest that there are several subcomplexes formed by Ldb1 and its interaction partners that can form larger, functional complexes (possibly via the homodimerisation of Ldb1). We can distinguish two large subcomplexes with either Ldb1 or Eto2 and one large complex containing both Ldb1 and Eto-2 (Fig. 3B and Fig. 7). Upon differentiation, association with Cdk9 is lost and the level of Eto-2 is substantially decreased, whereas the amount of Lmo4 is increased several fold. The reduction in association between Ldb1 and Eto-2 is also reflected in the reduced coimmunoprecipitation of E2-2 and Lyl1 with $\alpha$-Ldb1 and $\alpha$-Eto-2 in induced cells. In addition, these complexes appear to interact with Runx1, but we have as yet not been able to characterise this interaction due to the poor quality of the available antibody.

\section{Chromatin immunoprecipitations}

To confirm that Eto- 2 and Ldb1 are bound to chromatin at specific regulatory sites, we carried out chromatin immunoprecipitations using a number of erythroid genes: Gatal, Gypa, Myb, Myc and Eklf (Klfl - Mouse Genome Informatics), for which the binding of Gata1 complexes is known (Rodriguez et al., 2005). Among the Gatal gene regulatory regions, the HS-3.5 is known to bind the

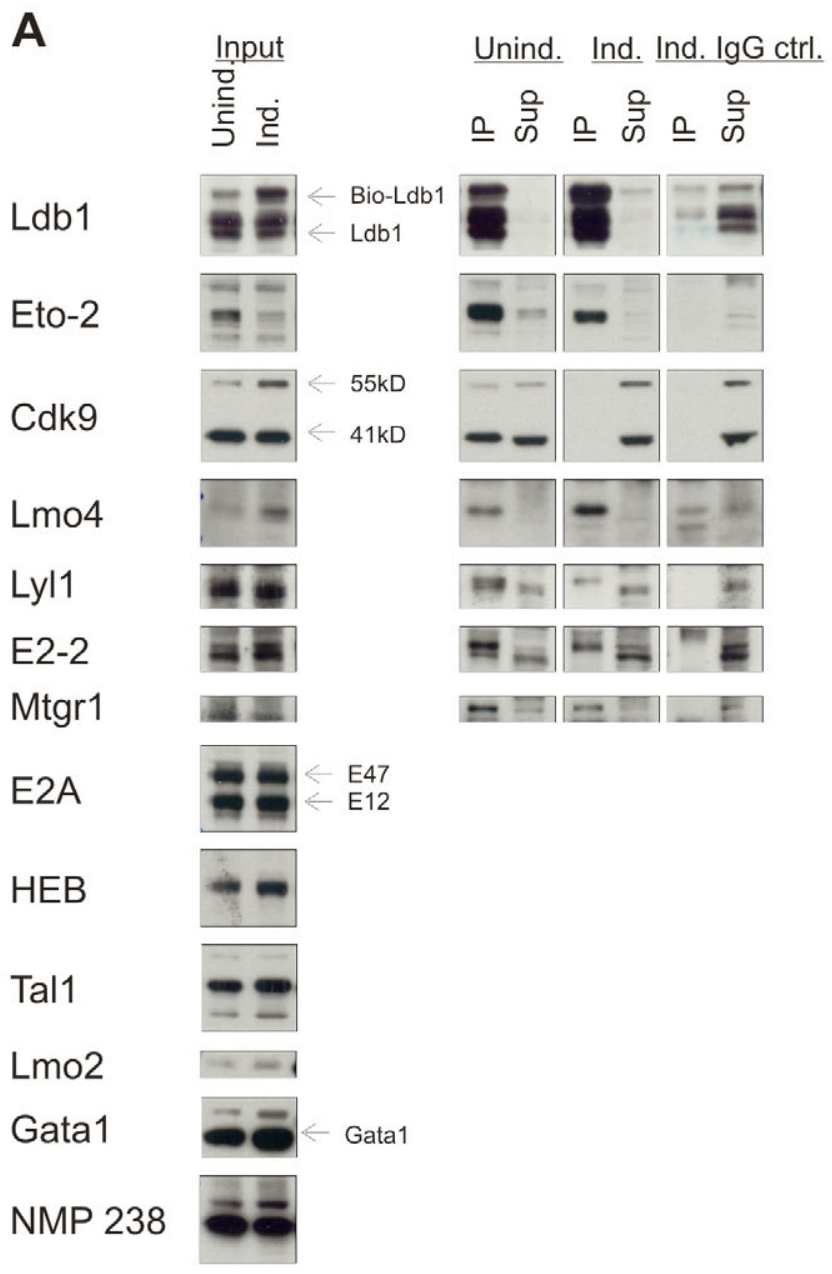

\begin{tabular}{|c|c|}
\hline B & 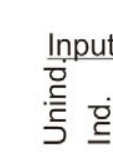 \\
\hline Ldb1 & \\
\hline Eto-2 & a \\
\hline Cdk9 & \\
\hline Lmo4 & \\
\hline Lyl1 & \\
\hline E2-2 & $==$ \\
\hline Mtgr1 & D \\
\hline $\mathrm{E} 2 \mathrm{~A}$ & $\overline{0}$ \\
\hline HEB & - \\
\hline Tal1 & \\
\hline Lmo2 & $n$ \\
\hline Gata1 & 40 \\
\hline NMP 238 & \\
\hline
\end{tabular}

Fig. 2. Analysis of Ldb1 interacting protein complexes. Protein levels of Eto-2, Cdk9 and Lmo4 change with induction of C88 cell differentiation. Western blot analysis of noninduced (Unind.) and induced (Ind.) C88 cells containing bio-Ldb1 (A) or untransfected C88 cell nuclear extracts (B). Input lanes indicate levels of tested proteins in untreated nuclear extracts diluted to the same concentration as in the immunoprecipitation experiments. Proteins immunoprecipitating with Ldb1 (IP lane) and supernatant (Sup) are shown and labelled accordingly. The isoforms of bio-Ldb1, Cdk9 and E2A, are indicated. 
A

$$
\text { 芌咅 旁 }
$$

\section{Ldb1}
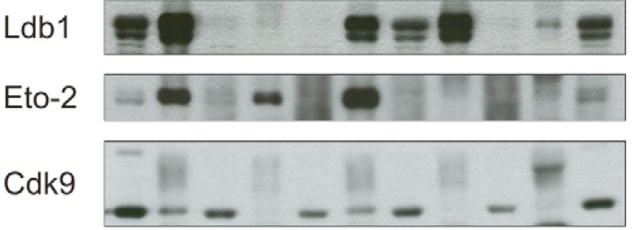

Lmo4

Lyl1

E2-2

E2A

Mtgr1

HEB

Tal1

Lmo2

Gata1
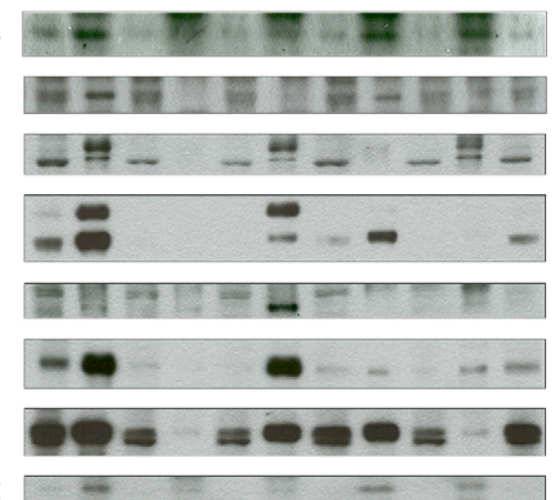

$-m-m-m-m-m-$
B

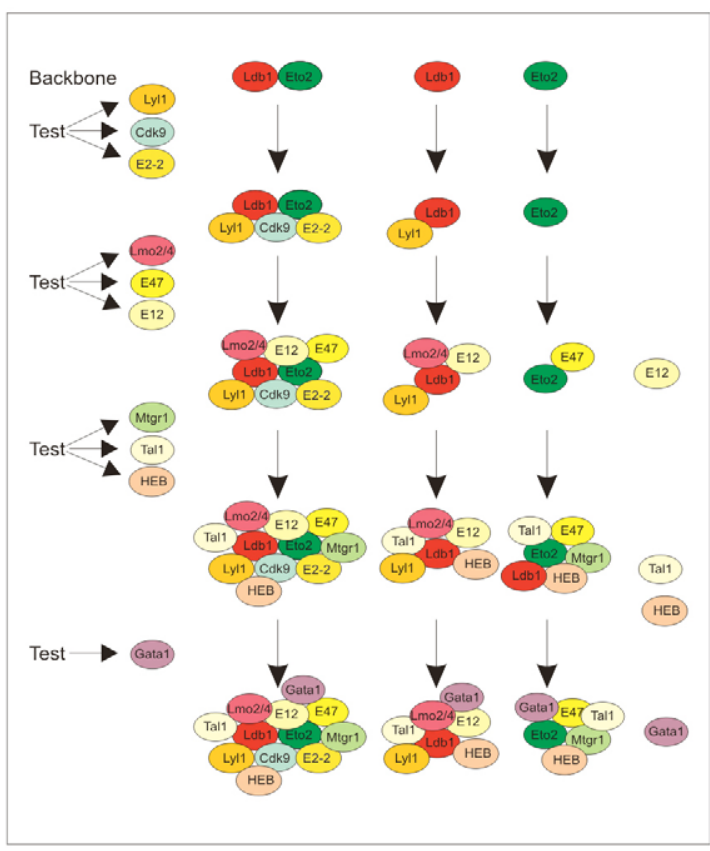

Fig. 3. Sequential immunoprecipitations to investigate Ldb1- and Eto-2-containing complexes. (A) Nuclear extracts of noninduced normal C88 cells were first depleted of either Ldb1 or Eto-2 with their respective antibodies. The supernatants were then incubated with $\alpha$-Eto-2 or $\alpha$ $\mathrm{Ldb} 1$, respectively. The second supernatant was also loaded to determine which proteins do not interact with either Eto-2 or Ldb1. IgG lanes are control immunoprecipitations carried out with a nonspecific, isotype-matched antibody. (B) Scheme of interacting factors from IP experiments in A (see also Fig. S1A in the supplementary material). Each new line represents the analysis of an additional three transcription factors.

Gata1/Tal1/Ldb1 complex, whereas the DNaseI hypersensitive site in the gene (Gata1 IE) does not (Guyot et al., 2004). The GATA-E box sites in the Gypa and Eklf promoters are also known targets of Gata1/Ldb1 (Lahlil et al., 2004; Rodriguez et al., 2005). In contrast, the $M y b$ and $M y c$ genes bind a Gata1/Gfilb complex (Rodriguez et al., 2005). In all cases we find an enrichment for Gatal (as expected) when compared with non GATA site negative control fragments (not shown) (Rodriguez et al., 2005). In contrast, Eto-2 and Ldb1 were bound to Gatal, Eklf and Gypa (Fig. 4), but not to $M y c$ and $M y b$ (not shown). The ratio of Eto-2/Ldb1 binding to the three elements, decreases during differentiation in C88 cells (Fig. 4) in accordance with the fact that there is less Ldb1/Eto-2 complex (see Fig. 2). Gata1, glycophorin A and Eklf proteins are expressed late in erythroid differentiation [the $-3.5 \mathrm{HS}$ of the Gatal gene also regulates Gatal expression in megakaryocytic cells (McDevitt et al., 1997; Onodera et al., 1997)], whereas $M y c$ and $M y b$ are
$E K L F$
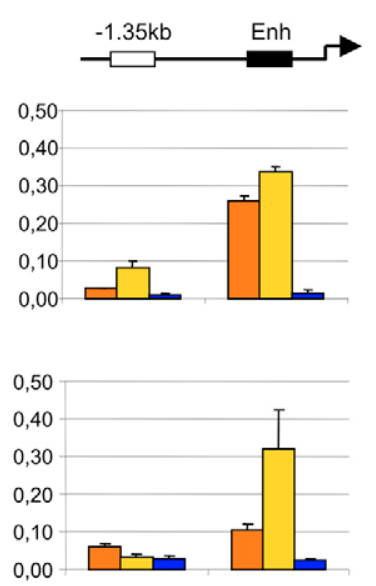

Gata1
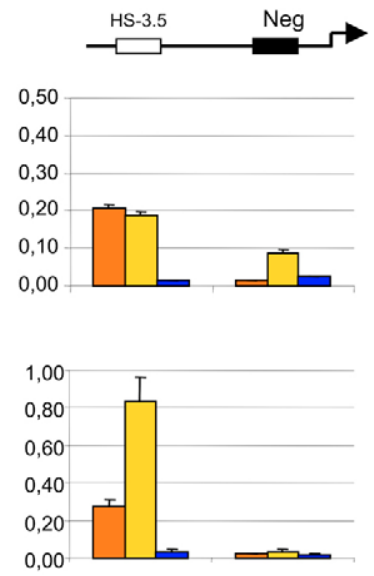

\section{GlycophorinA}

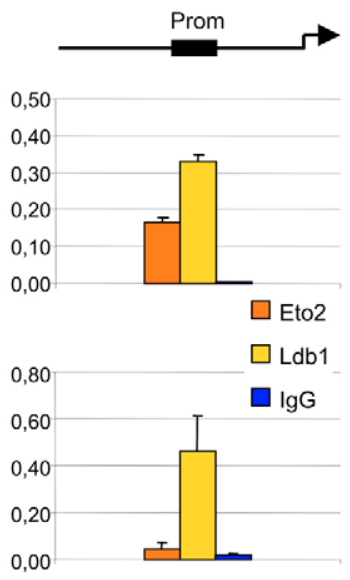

Fig. 4. ChIP of Ldb1 and Eto-2. (Top) The boxes indicate the localisation of the upstream $\mathrm{HS}$ in the Eklf, Gata1 and Gypa promoters that contain Gata-1/Tal 1 binding sites and negative controls not containing such sites. Bar graphs show the relative enrichment of sequences immunoprecipitated by Eto-2 (red), Ldb1 (yellow) and the IgG control (blue) in noninduced (middle row) and induced (bottom row) C88 cells. All values were normalised to a GAPDH control. 
downregulated. The decrease of Eto- 2 levels in late erythroid cells suggests that Eto-2 adds a repressive function to the Gata1/Tal1/Ldb1 complex to keep late erythroid genes off early during differentiation. In contrast, Eto-2 is not essential for Gfilb repressed genes such as $M y b$ and $M y c$ expressed at early stages (Rodriguez et al., 2005).

\section{Eto-2, Cdk9 and Lmo4 are required for definitive haematopoiesis in a zebrafish model system}

Ldb1 and its constitutive binding partners Lmo2 and Tal1 are essential for embryonic blood formation (Warren et al., 1994; Robb et al., 1995; Shivdasani, 1995). We next asked whether the newly identified Ldb1 interacting partners E2A, Cdk9, Eto-2, Lmo4 and Mtgr1 are required for haematopoietic development. As the genetic regulation of embryonic and definitive haematopoiesis is highly conserved between zebrafish and mammals, we tested the role of these proteins by MO-mediated inhibition of mRNA translation in zebrafish embryos (Nasevicius and Ekker, 2000). In zebrafish, primitive erythrocytes expressing embryonic haemoglobin derive from the intra-embryonic intermediate cell mass (ICM) and start circulating at $24 \mathrm{hpf}$. Shortly thereafter, with development of the definitive haematopoietic system, a ventrally located $f l k l$-positive subpopulation of the dorsal aorta precursors starts to express runxl. runxl is also expressed in primitive erythrocytes, the olfactory epithelium, Rohon-Beard neurons (Kalev-Zylinska et al., 2002) and the anterior paraxial mesoderm.

ATG-MOs and mutated MOs targeted against the zebrafish orthologues of Cdk9, Eto-2, Lmo4, Mtgrl and Ldbl were injected at three increasing doses into one- to eight-cell stage embryos. To test the effects of these MOs on the embryonic and definitive haematopoeitic system, we analysed embryos after onset of blood circulation by in situ hybridisation with probes against embryonic $\beta E 1$ and runxl, respectively (Fig. 5).

Ldb1-MO-injected embryos displayed variable phenotypes at all doses, including deformation of the body axis, dysmorphic somites, abnormal tail morphology, haematopoietic defects resembling that of
A
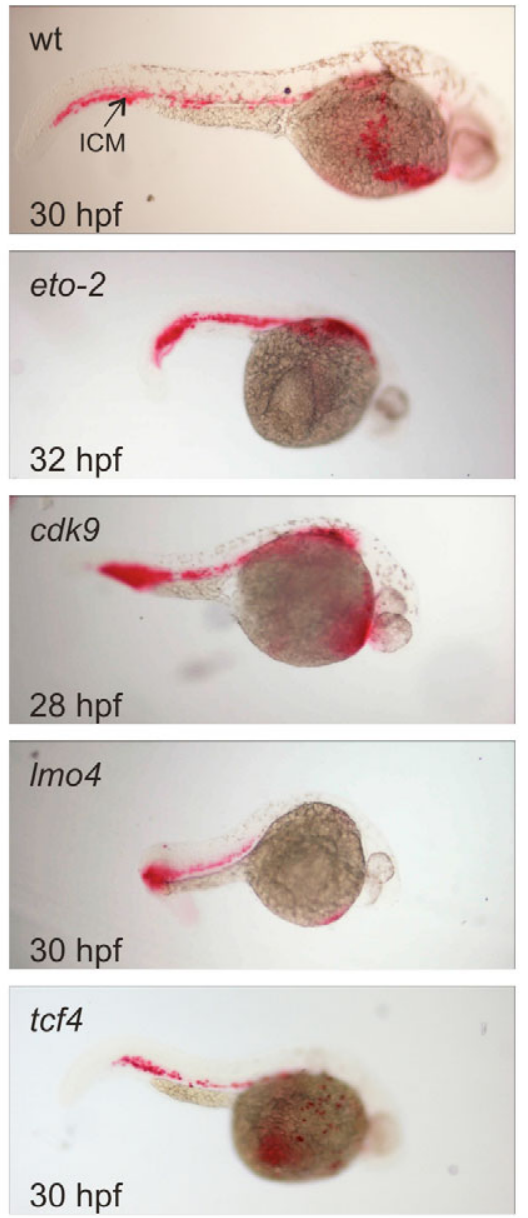

zE1b-globin
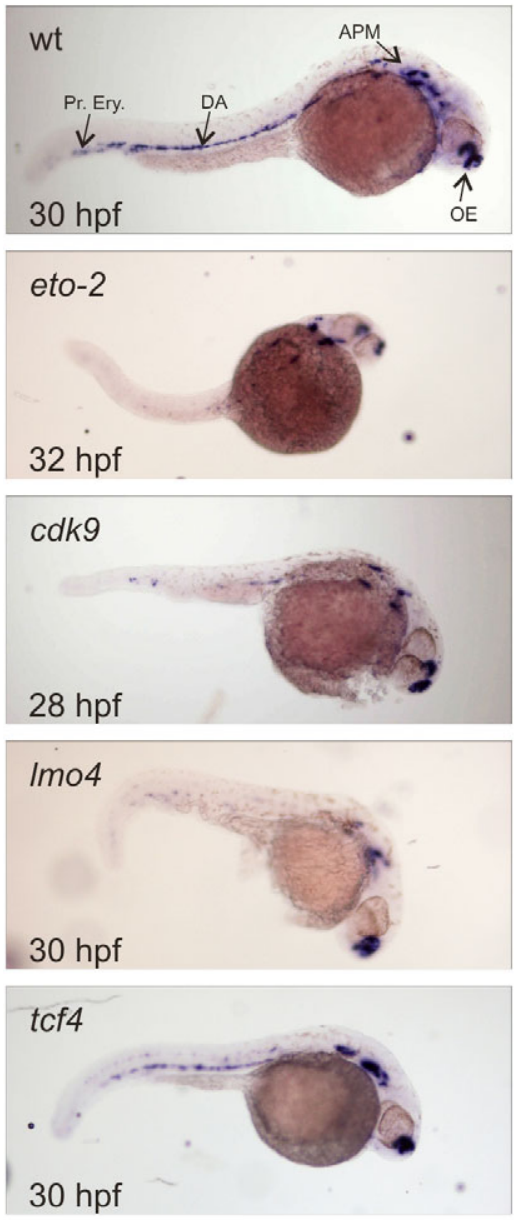

zrunx 1
B
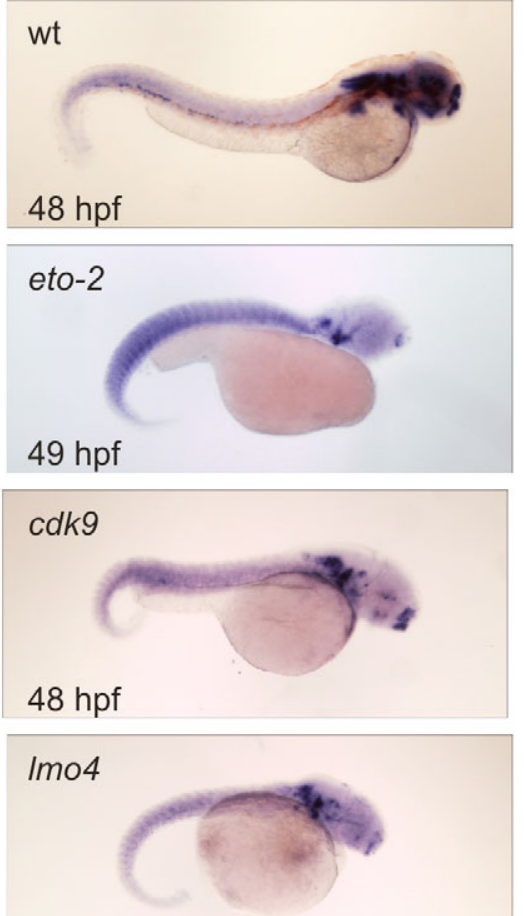

$50 \mathrm{hpf}$

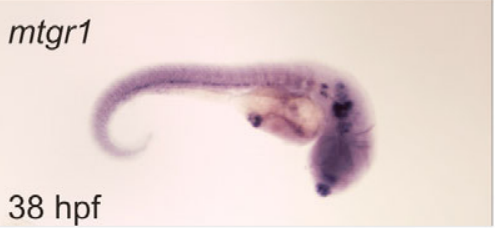

zrunx1

Fig. 5. Analysis of zebrafish embryos after MO injections. The developmental stage of each embryo is in the bottom left corner; the targeted gene is indicated in the top left corner. All pictures were taken at the same magnification. (A) Noninjected wild-type (wt) control embryos stained for $\beta E 1$ - (zE1b-globin, left column) and runx1-mRNAs (right column). The ICM, dorsal aorta (DA), primitive erythrocytes (Pr.Ery.), anterior paraxial mesoderm (APM) and olfactory epithelium (OE) are indicated. The $\beta E 1$ signal is red, runx 1 signal is blue. Treated embryos were injected with 1 pmol eto-2-MO (32 hpf), 1 pmol cdk9-MO (28 hpf), 1 pmol Imo4-MO (30 hpf), or with 0.5 pmol of the control tcf4-MO (30 hpf). (B) The reduction of runx 1 expression in the dorsal aorta region resulting from injection with the MOs directed against eto-2 $(n=23 / 27)$, cdk9 ( $n=33 / 56)$ and $/ \mathrm{mo} 4$ $(n=36 / 54)$ was still observable after 2 days. Embryos injected with the $m$ tgr1-MO were analysed at $38 \mathrm{hpf}$ and showed only a slight effect on the definitive haematopoietic system. All embryos shown were injected with 1 pmol of the corresponding MO. 
the mouse (A.H., unpublished) and necrosis in the brain (not shown). The severity of defects increased with increasing dose of injected Ldb1-MO. As a negative control, we used mutated ATG-MOs and an MO targeted against $t c f 4$, the zebrafish orthologue of $T c f 7 / 2$. The latter is not expressed in haematopoietic tissues and, when deleted, has a specific effect in the intestinal epithelium of the mouse (Korinek et al., 1998). As expected, no effects of the mutated ATG-MOs (not shown) or tcf4-MO on the haematopoietic system were observed in the injected zebrafish at any dose. Embryos injected with the highest dose of $t c f 4$-MO displayed some tail abnormalities.

The $c d k 9-\mathrm{MO}$ had no effect on $\beta E 1$ expression or expression of runxl in the primitive erythrocytes located in the posterior ICM, the olfactory epithelium and the anterior paraxial mesoderm. However, they had a severe effect on definitive erythropoiesis. A 0.5 -pmol dose of $c d k 9-\mathrm{MO}$ showed a clear reduction of runxl signal in the dorsal aorta region $(n=10 / 18)$, which decreased further in embryos injected with $1 \mathrm{pmol}(n=8 / 10)$. Surprisingly the effect appears to be specific to the haematopoietic system, although $C d k 9$ is expressed in many tissues (Bagella et al., 1998).

Embryos injected with the eto-2-MOs had a similar phenotype. The reduction of runxl expression in embryos injected with 0.5 pmol $(n=13 / 16)$ and 1 pmol of eto-2-MO $(n=5 / 7)$ was more severe compared with the $c d k 9-\mathrm{MO}$ : runx 1 in the dorsal aorta was either almost or completely abolished. Embryonic $\beta E 1$ expression was normal in all eto-2-MO-injected embryos; however, some primitive erythrocytes in the caudal region were located laterally to the midline as opposed to their location in wild-type embryos. This is similar to the effect observed when sonic hedgehog signalling is inhibited (Gering and Patient, 2005), suggesting that eto-2 may play a role in the response to extracellullar signals. Injection of 1-2 pmol of the mtgrl-MO did not affect embryonic haematopoiesis. Some reduction of runxl expression in dorsal aorta precursor cells was observed at 38 hpf ( $n=5 / 25 ;$ Fig. 5B).

Embryos treated with the lmo4-MO were comparable to knockdowns of $c d k 9$ and eto-2. Expression of embryonic $\beta E 1$ was normal, whereas reduced levels of runxl were observed in the dorsal aorta region at $0.5 \mathrm{pmol} \mathrm{MO}(n=8 / 13)$ and decreased further with lmo4-MO injected at 1 pmol. In addition, some of the treated embryos appeared to have brain or neural tube abnormalities, which are the cause of perinatal death of the corresponding knockout mouse (Hahm et al., 2004; Tse et al., 2004; Lee et al., 2005). These mice showed no defects in the haematopoietic system, although only half of the homozygous Lmo4 null mutants were born. The other half died around E9 of gestation, possibly due to a haematopoietic phenotype. The effects of the eto-2-, cdk9- and lmo4-MOs on the definitive haematopoietic system were still observable after 2 days (Fig. 5B) with normally circulating embryonic blood cells. At this stage of development the reduction in body size of the embryos injected with the eto-2-, cdk9-, lmo4- and mtgrl-MOs also became more apparent (Fig. 5B).

We conclude that the newly identified Ldb1 interaction partners eto-2, cdk9 and $1 m o 4$ are essential for definitive erythropoiesis in zebrafish, whereas mtgr1 plays a less critical role. The fact that embryonic haematopoieis is intact shows that the expression of tall and gatal is not affected by knockdown of eto-2, $c d k 9$ and $l m o 4$. The dorsal aorta is normally formed in such treated embryos, indicating that the eto-2, cdk9 and $l m o 4$ are not required for vasculogenesis. It is noteworthy in this context that Eto-2 in zebrafish (this paper) and most of its constitutive binding partners, namely HEB and E47 in mouse (Zhuang et al., 1996) and Mtgr1 in mouse (Amann et al., 2005) and zebrafish (this paper), are not required for embryonic haematopoiesis.

\section{Ldb1 interacting partners are expressed in the same cells in the para-aortic splanchnopleura of the early mouse embryo.}

The results obtained for the novel Ldb1 interaction partners in the zebrafish suggest that they would be expressed in the early mouse embryo at stages prior to the 'birth' of the definitive haematopoietic stem cells in the AGM (Durand and Dzierzak, 2005). We therefore performed immunohistochemistry and immunofluorescence on E9.5 embryo sections (Fig. 6). Immunohistochemical analysis with $\alpha$ Ldb1, $\alpha$-E2A, $\alpha$-Lmo2, $\alpha$-Gata1, $\alpha$-Eto- 2 and $\alpha$-Cdk9 showed that all are expressed in the para-aortic splanchnopleura (P-Sp), the region destined to contribute to the AGM (Fig. 6A,B).

To further determine the expression pattern of the interacting proteins and to confirm that cells within the P-Sp co-express these proteins, we performed in situ immunofluorescence experiments on the cryosections. We found that cells positive for Gatal expression also expressed Eto-2, Ldbl and Runxl (Fig. 6C). Cells expressing $L d b 1$ were also positive for Runx1, E2A and Lmo2 (not shown). Although we cannot analyse all of the proteins due to antibody incompatibilities, the observation that Gatal and Eto-2, Gatal and $L d b 1$, and $L d b 1$ and Runx 1 are co-expressed in the pre-AGM cells of the P-Sp suggests that they form a complex that may be essential for the induction of the definitive haematopoietic system. The fact that Eto-2 is predominantly cytoplasmic at that time (Fig. 6C, column 3, panels Eto-2 and merge) suggests that it may respond to extracellullar signals at the prehaematopoietic stage. At later stages (fetal liver), it is abundant in the nucleus but its cytoplasmic expression is very weak. (see Fig. S2 in the supplementary material).

\section{DISCUSSION Ldb1 forms dynamic complexes during erythroid differentiation}

By using a systems biology approach we identified all known and many new binding partners of Ldb1 and determined their importance for haematopoietic development. The important implication of this work is that the analysis of proteins co-expressed and interacting with each other in a late mature cell type are already implicated at the earliest stages of, in this case, blood development.

The Ldb1 proteome has a number of interesting interactions: (1) with Eto-2 (and Mtgr1); (2) with a large number of different bHLH proteins; (3) with Cdk9; and (4) with the Ssdp proteins, although this latter interaction was not analysed further. Recently we have shown that Gata1 forms at least five clearly identifiable protein complexes (Rodriguez et al., 2005). We did not observe such distinct complexes for Ldb1. Clearly, Ldb1 forms a core complex with the known partners Gata1, Tal1, Lmo2 and E2A, and the newly identified partner Eto-2 (Fig. 6). Eto-2 also forms complexes with E2A and Tal1 without Ldb1. In the sequential immunoprecipitations we can distinguish between the preferential binding partners of Eto-2 and Ldb1, and deduce the existence of a higher order complex the formation of which is favoured in proliferating cells. At the same time it is difficult to separate groups of interacting proteins from each other by immunoprecipitations, especially if a protein interacts with others in different combinations. Hence, we are in the process of purifying the different complexes. With induction, levels of Eto2 decrease and formation of the large complex is lower (Fig. 7). Cdk9, which has been linked to cell-cycle progression (BettencourtDias et al., 2004), would no longer be part of the complex. This may explain why the cells stop proliferating upon differentiation. At the same time, the levels of Lmo4 increase, possibly replacing Lmo2/Eto-2 and leading to an activation of transcription of genes expressed after terminal differentiation. 

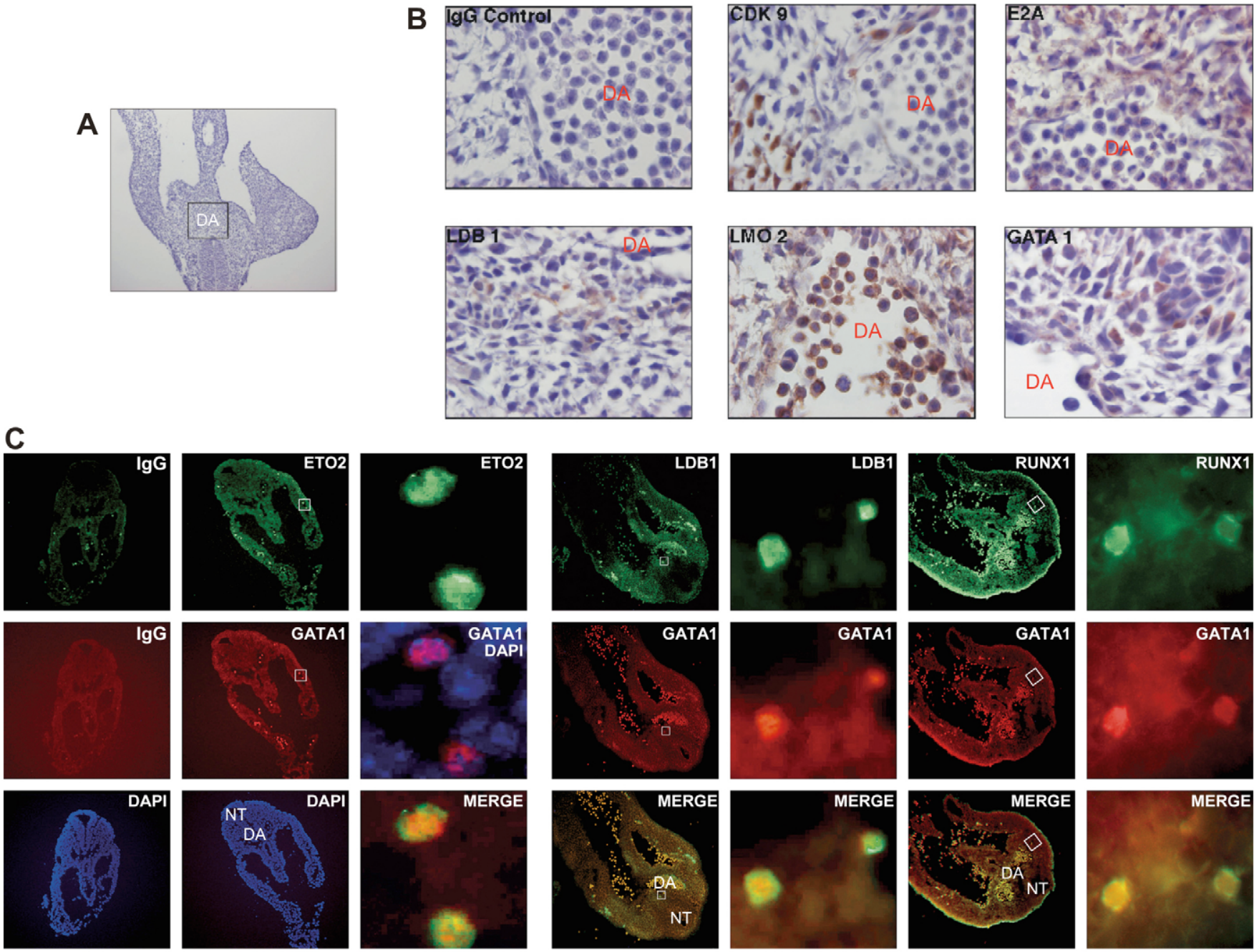

Fig. 6. Ldb1 interacting partners are expressed in the P-Sp. (A) Haematoxylin stained $10 \mu \mathrm{m}$ transversal cryosection of a E9.5 FVB embryo. The area of the P-Sp is indicated by the box. (B) High magnification (X1000) of the areas such as shown in (A). Expression of Cdk9, E2A, Ldb1, Lmo2 and Gata1 was detected with specific antibodies and visualised with DAB. IgG panel shows the background staining with an unspecific lgG antibody. (C) Immunofluorescence analysis of E9.5 embryos with $\alpha$-Eto-2, $\alpha$-Ldb1, $\alpha$-Runx1 and $\alpha$-Gata1 antibodies. Specific staining is seen for both Eto-2 (green) and Gata1 (red) antibodies (second column), compared with the lgG control (first column). (Third column) Enlargement of the section shown in the second column. Merge is a superposition of images of the Eto-2 and Gata1 detection; cells that express both Eto-2 and Gata1 appear as yellow. The overlay of Gata1 and DAPI staining shows exclusive nuclear localisation of Gata1, whereas Eto-2 is seen in the nucleus and cytoplasm. (Fourth column) Ldb1- (green) and Gata1- (red) expressing cells are located in the dorsal aorta region; most of the cells positive for Ldb1 are also positive for Gata1 (Ldb1 is also expressed in other cell types). A similar pattern is shown for Gata 1- (red) and Runx1- (green) expressing cells in E9.5 embryos (sixth column). (Fifth and seventh columns) High magnification of the same sections reveals more detail. DA, dorsal aorta; NT, neural tube.

Noteworthy is the presence of a large number of DNA binding proteins within the complex, particularly the presence of at least five bHLH proteins and the zinc finger transcription factor Gata1. It is possible that such a complex may very well be involved in the establishment and/or facilitation of long-range interactions, processes in which Ldb1 has been implicated (Morcillo et al., 1997). Specifically, in Drosophila melanogaster, Chip was identified in a screen for factors involved in the long-range gene activation of the cut gene. Chip was proposed to bridge the Pannier (GATA) and Achaete/Scute (bHLH) complexes causing the intervening DNA to loop out bringing DNA control elements into close proximity (Ramain et al., 2000). The erythroid Ldb1-Lmo2-Tal1-E2A-Gata1 complex may have a similar role. It was recently shown that the complex binds to multiple sites in the $\alpha$-globin locus (Anguita et al.,
2004). We envisage that these complexes also interact and promote long-range interactions in other gene loci, for example in the $\beta$ globin locus ACH (Tolhuis et al., 2002).

The Eto family members Eto-2 and Mtgr1 are thought to be repressors by binding the NCor/Sin3A/HDAC1 (Gelmetti et al., 1998; Lutterbach et al., 1998; Wang et al., 1998) complex. Eto-2 was the most abundant protein in the MS analysis, suggesting it is a direct (and crucial) binding partner of Ldb1 (confirmed by immunoprecipitations). We also observed that Eto-2 and its family member Mtgr1 interact with each other. Moreover Eto-2 appears to be the bridging factor for Ldb1 to interact with Mtgr1 (Fig. 3, and see Fig. S1A in the supplementary material). Eto proteins and the D. melanogaster orthologue nervy have four highly conserved protein interaction domains (Davis et al., 1999; 


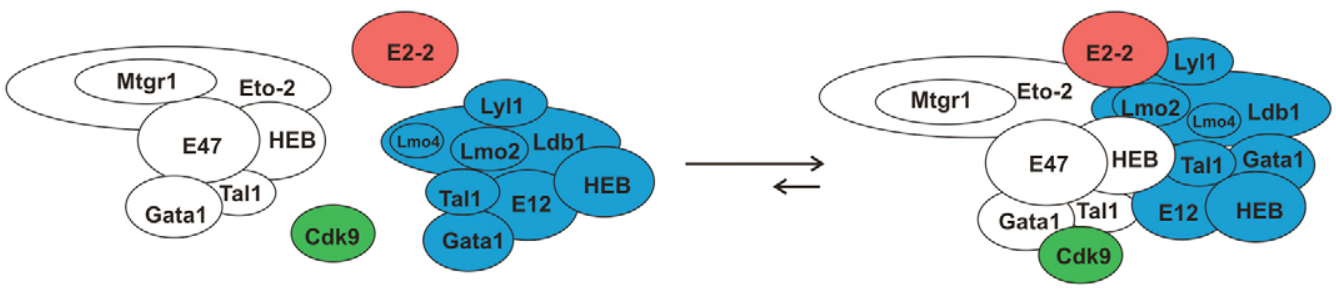

Fig. 7. Model of Ldb1 complexes in uninduced MEL cells. The horizontal arrows indicate that the balance of interaction is towards the large complex in proliferating noninduced cells. Upon the induction of differentiation and termination of proliferation the level of Eto-2 drops whereas the level of Lmo4 rises, hence the equilibrium would shift towards the smaller complexes. The presence of several DNA binding proteins in a single complex may explain the role of $\mathrm{Ldb} 1$ as a facilitator of long-range interactions.

Davis et al., 2003). The DNA binding of the Eto-2 complexes we describe probably occurs through its bHLH binding partners and/or Gata1.

Interestingly, with induction Eto- 2 and the Eto-2/Ldb1 complex decrease, while the level of Lmo4 increases. Thus, the level of the large Ldb1-Eto-2 complex drops to be replaced by one with Lmo4. Complementary results were obtained by other groups through characterisation of Tal1 complexes (Schuh et al., 2005; Goardon et al., 2006). As indicated by the chromatin immunoprecipitation experiments, the repressive role of Eto-2 may very well explain how late erythroid genes become activated. An alternative or complementary explanation may be post-translational protein modifications of the Eto-2 complex members, a possibility that cannot be excluded at present.

A good candidate to carry out modifications and change specific interactions is $\mathrm{Cdk} 9$. This CDC2 orthologue precipitated differentially with Ldb1 in proliferating and differentiating C88 cells. The invariance of the main isoform independent of the cell-cycle stage has been reported (Garriga et al., 2003). Cdk9 is thought to have two functions: regulating RNA polymerase II by phosphorylating its C-terminal domain (Marshall et al., 1996; Zhu et al., 1997); and regulating the cell cycle. A 'knockdown' of the D. melanogaster orthologue of $C d k 9$ causes an arrest at the G1 to S transition (Bettencourt-Dias et al., 2004), congruent with the in vitro data that the human $C D K 9$ orthologue phosphorylates Rb (Graña et al., 1994). Interestingly, Gata1 has been found to interact with Rb in vitro (Whyatt et al., 1997). We detect an interaction between $\mathrm{Cdk} 9$ and $\mathrm{Ldb} 1$ only in noninduced, proliferating C88 cells, suggesting Ldb1 and its partners might be involved in transcriptional control of the cell cycle through the dual function of Cdk9. Putative target genes could be E2F family members expressed in haematopoietic cells. Cdk9 also interacts with BRG1 and STAT3 to activate transcription of the cell-cycle inhibitor p21waf1 (Giraud et al., 2004), suggesting that Cdk9 has different functions in the cell cycle depending on its partners. In this context it is interesting that we detect Eto-2 protein in the cytoplasm of haematopoietic stem cell precursors (Fig. 6) and of developing neurons (N.M., unpublished). Eto-2 may respond to extracellular signals by translocating from the cytoplasm into the nucleus, while it is downregulated in terminally differentiating cells. This suggests that Eto-2 plays a key role in the development of the definitive HSCs, and is required for the subsequent phases of expansion of the different lineages. It then needs to be downregulated to allow the activation of late genes such as Eklf for terminal differentiation.

\section{Late erythroid differentiation complexes and early haematopoiesis}

It is remarkable that the analysis of interacting proteomes of Gata1 (Rodriguez et al., 2005) and Ldb1 (this paper) in late erythroid cells has resulted in the identification of a number of proteins essential for early haematopoiesis (as found in the zebrafish experiments), in particular Lmo4, Cdk9 and Eto-2.

Lmo4 expression in mice has been detected at E9 from the caudal region of the dorsal and lateral paraxial mesoderm up to the direct vicinity of the dorsal aorta, suggesting that Lmo4 could play a role in HSC formation (Kenny et al., 1999). Lmo4 is also upregulated in late $\mathrm{T}$ cell differentiation (Kenny et al., 1999) similar to that observed in C88 cells. In Xenopus, Xlmo4 and Gata-2 act synergistically in ventral mesoderm formation. However, an Xlmo4-MO did not prevent ventral mesoderm formation (de la Calle-Mustienes et al., 2003). In zebrafish, lmo4 is expressed at gastrulation but not during ventral mesoderm formation (Lane et al., 2002). In accordance with this, we found embryonic haematopoiesis in lmo4-MO-treated zebrafish embryos to be normal. We show the expression of $1 \mathrm{mo} 4$ at later stages to be important for the formation of definitive HSCs in zebrafish. Whether the same phenotype is observed in mice remains to be determined.

MO-mediated repression of eto- 2 had the most drastic phenotype in zebrafish - absence of runxl expression in embryonic erythrocytes and lack of definitive haematopoiesis, suggesting it is essential for runxl expression at that stage. Cdk9-MO-treated embryos lacked definitive cells. However in embryonic blood cells runxl expression was detected, suggesting $C d k 9$ does not regulate runxl directly.

The fact that these factors are already co-expressed in the same cells in the murine P-Sp before the generation of the definitive HSCs in the AGM (de Bruijn et al., 2000) suggests that they are also essential for definitive haematopoiesis in the mouse. Eto-2 and Cdk9 may be more important in this process than Gata1, because loss of Gata1 is not deleterious to these very early stages (with cytoplasmic Eto-2). This in turn suggests that Tal1, Ldb1 and Lmo2 are dominant at this stage. Because all of the Ldb1-bound Gata1 is complexed with Eto-2, we postulate that when Eto-2 translocates from the cytoplasm to the nucleus, the balance of interactions is changed causing the transition to a more proliferative Gata1-driven phase followed by terminal differentiation.

We are grateful to Drs S. Orkin, R. Baer and G. Gill for the $\alpha$-Lmo2, $\alpha$-Tal1 and $\alpha$-Ldb1 antibodies and Dr S. Schulte-Merker for help with the zebrafish injections. N.M. was supported by a DFG Fellowship, A.H. was supported by a Marie Curie Fellowship. This work is supported by the NWO (NL), the NIH and the $\mathrm{EU}(\mathrm{CiO})$. 
Supplementary material

Supplementary material for this article is available at

http://dev.biologists.org/cgi/content/full/133/24/4913/DC1

\section{References}

Agulnick, A. D., Taira, M., Breen, J. J., Tanaka, T., Dawid, I. B. and Westphal, H. (1996). Interactions of the LIM-domain-binding factor Ldb1 with LIM homeodomain proteins. Nature $\mathbf{3 8 4}, \mathbf{2 7 0 - 2 7 2}$

Amann, J. M., Chyla, B. J., Ellis, T. C., Martinez, A., Moore, A. C., Franklin, J. L., McGhee, L., Meyers, S., Ohm, J. E., Luce, K. S. et al. (2005). Mtgr1 is a transcriptional corepressor that is required for maintenance of the secretory cell lineage in the small intestine. Mol. Cell. Biol. 25, 9576-9585.

Anguita, E., Hughes, J., Heyworth, C., Blobel, G. A., Wood, W. G. and Higgs, D. (2004). Globin gene activation during haemopoiesis is driven by protein complexes nucleated by GATA1 and GATA-2. EMBO J. 23, 2841-2852.

Antoniou, M. (1991). Induction of erythroid-specific expression in murine erthroleukemia (MEL) cell lines. In Methods in Molecular Biology, Gene Transfer and Expression Protocols, Vol. 7 (ed. E. J. Murray), pp. 421-434. Totowa, NJ: The Humana Press Inc.

Bagella, L., MacLachlan, T. K., Buono, R. J., Pisano, M. M., Giordano, A. and De Luca, A. (1998). Cloning of murine CDK9/PITALRE and its tissue-specific expression in development. J. Cell Physiol. 177, 206-213

Bettencourt-Dias, M., Giet, R., Sinka, R., Mazumdar, A., Lock, W. G., Balloux, F., Zafiropoulos, P. J., Yamaguchi, S., Winter, S., Carthew, R. W. et al. (2004). Genome-wide survey of protein kinases required for cell cycle progression. Nature $\mathbf{4 3 2}$, 980-987.

Brand, M., Ranish, J. A., Kummer, N. T., Hamilton, J., Igarashi, K., Francastel, C., Chi, T. H., Crabtree, G. R., Aebersold, R. and Groudine, M. (2004). Dynamic changes in transcription factor complexes during erythroid differentiation revealed by quantitative proteomics. Nat. Struct. Mol. Biol. 11, 73-80.

Cantor, A. B. and Orkin, S. (2001). Hematopoietic development: a balancing act. Curr. Opin. Genet. Dev. 11, 513-519.

Chen, L., Segal, D., Hukriede, N. A., Podtelejnikov, A. V., Bayarsaihan, D., Kennison, J. A., Ogryzko, V. V., Dawid, I. B. and Westphal, H. (2002). Ssdp proteins interact with the LIM-domain-binding protein Ldb1 to regulate development. Proc. Natl. Acad. Sci. USA 99, 14320-14325.

Cumano, A., Ferraz, J. C., Klaine, M., Di Santo, J. P. and Godin, I. (2001) Intraembryonic, but not yolk sac hematopoietic precursors, isolated before circulation, provide long-term multilineage reconstitution. Immunity 15, 477485

Davis, J. N., Williams, B. J., Herron, J. T., Galiano, F. J. and Meyers, S. (1999). ETO-2, a new member of the ETO-family of nuclear proteins. Oncogene $\mathbf{1 8}$ 1375-1383.

Davis, J. N., McGhee, L. and Meyers, S. (2003). The ETO (MTG8) gene family. Gene 303, 1-10.

de Boer, E., Rodriguez, P., Bonte, E., Krijgsveld, J., Katsantoni, E., Heck, A., Grosveld, F. and Strouboulis, J. (2003). Efficient biotinylation and single-step purification of tagged transcription factors in mammalian cells and transgenic mice. Proc. Natl. Acad. Sci. USA 100, 7480-7485.

de Bruijn, M. F., Speck, N. A., Peeters, M. C. and Dzierzak, E. (2000). Definitive hematopoietic stem cells first develop within the major arterial regions of the mouse embryo. EMBO J. 19, 2465-2474.

de Bruijn, M. F., Ma, X., Robin, C., Ottersbach, K., Sanchez, M. J. and Dzierzak, E. (2002). Hematopoietic stem cells localize to the endothelial cell layer in the midgestation mouse aorta. Immunity 16, 673-683.

de la Calle-Mustienes, E., Lu, Z., Cortes, M., Andersen, B., Modolell, J. and Gomez-Skarmeta, J. (2003). Xenopus XImo4 is a GATA cofactor during ventral mesoderm formation and regulates $L d b 1$ availability at the dorsal mesoderm and the neural plate. Dev. Biol. 264, 564-581.

Durand, C. and Dzierzak, E. (2005). Embryonic beginnings of adult hematopoietic stem cells. Haematologica 90, 100-108.

Garriga, J., Bhattacharya, S., Calbo, J., Marshall, R. M., Truongcao, M., Haines, D. S. and Graña, X. (2003). CDK9 is constitutively expressed throughout the cell cycle, and its steady-state expression is independent of SKP2. Mol. Cell. Biol. 23, 5165-5173.

Gekas, C., Dieterlen-Lievre, F., Orkin, S. H. and Mikkola, H. (2005). The placenta is a niche for hematopoietic stem cells. Dev. Cel/ 8, 365-375. Gelmetti, V., Zhang, J., Fanelli, M., Minucci, S., Pelicci, P. G. and Lazar, M. (1998). Aberrant recruitment of the nuclear receptor corepressor-histone deacetylase complex by the acute myeloid leukemia fusion partner ETO. Mol. Cell. Biol. 18, 7185-7191

Gering, M. and Patient, R. (2005). Hedgehog signaling is required for adult blood stem cell formation in zebrafish embryos. Dev. Cell 8, 389-400.

Giraud, S., Hurlstone, A., Avril, S. and Coqueret, O. (2004). Implication of BRG1 and cdk9 in the STAT3-mediated activation of the p21waf1 gene. Oncogene 23, 7391-7398

Goardon, N., Lambert, J. A., Rodriguez, P., Nissaire, P., Herblot, S., Thibault, P., Dumenil, D., Strouboulis, J., Romeo, P. H. and Hoang, T. (2006). ETO2 coordinates cellular proliferation and differentiation during erythropoiesis. EMBO J. 25, 357-366.

Graña, X., De Luca, A., Sang, N., Fu, Y., Claudio, P. P., Rosenblatt, J., Morgan, D. O. and Giordano, A. (1994). PITALRE, a nuclear CDC2-related protein kinase that phosphorylates the retinoblastoma protein in vitro. Proc. Natl. Acad. Sci. USA 91, 3834-3838.

Guyot, B., Valverde-Garduno, V., Porcher, C. and Vyas, P. (2004). Deletion of the major GATA1 enhancer HS 1 does not affect eosinophil GATA1 expression and eosinophil differentiation. Blood 104, 89-91.

Hahm, K., Sum, E. Y., Fujiwara, Y., Lindeman, G. J., Visvader, J. E. and Orkin, S. H. (2004). Defective neural tube closure and anteroposterior patterning in mice lacking the LIM protein LMO4 or its interacting partner Deaf-1. Mol. Cell. Biol. 24, 2074-2082.

Jowett, T. and Yan, Y. L. (1996). Double fluorescent in situ hybridization to zebrafish embryos. Trends Genet. 12, 387-389.

Kalev-Zylinska, M. L., Horsfield, J. A., Flores, M. V., Postlethwait, J. H., Vitas, M. R., Baas, A. M., Crosier, P. S. and Crosier, K. (2002). Runx1 is required for zebrafish blood and vessel development and expression of a human RUNX1CBF2T1 transgene advances a model for studies of leukemogenesis. Development 129, 2015-2030.

Kenny, D. A., Jurata, L. W., Saga, Y. and Gill, G. (1999). Identification and characterization of $\mathrm{LMO4}$, an $\mathrm{LMO}$ gene with a novel pattern of expression during embryogenesis. Proc. Natl. Acad. Sci. USA 95, 11257-11262.

Korinek, V., Barker, N., Moerer, P., van Donselaar, E., Huls, G., Peters, P. J. and Clevers, H. (1998). Depletion of epithelial stem-cell compartments in the small intestine of mice lacking Tcf-4. Nat. Genet. 19, 379-383.

Lahlil, R., Lecuyer, E., Herblot, S. and Hoang, T. (2004). SCL assembles a multifactorial complex that determines glycophorin A expression. Mol. Cell. Biol. 24, 1439-1452.

Lane, M. E., Runko, A. P., Roy, N. M. and Sagerström, C. (2002). Dynamic expression and regulation by Fgf8 and Pou2 of the zebrafish LIM-only gene, Imo4. Gene Expr. Patterns 2, 207-211.

Lee, S. K., Jurata, L. W., Nowak, R., Lettieri, K., Kenny, D. A., Pfaff, S. L. and Gill, G. (2005). The LIM domain-only protein LMO4 is required for neural tube closure. Mol. Cell. Neurosci. 28, 205-214.

Liu, H. and Herrmann, C. (2005). Differential localization and expression of the Cdk9 42k and 55k isoforms. J. Cell Physiol. 203, 251-260.

Lutterbach, B., Westendorf, J. J., Linggi, B., Patten, A., Moniwa, M., Davie, J. R., Huynh, K. D., Bardwell, V. J., Lavinsky, R. M., Rosenfeld, M. G. et al. (1998). ETO, a target of $t(8 ; 21)$ in acute leukemia, interacts with the N-CoR and mSin3 corepressors. Mol. Cell. Biol. 18, 7176-7184.

Marshall, N. F., Peng, J., Xie, Z. and Price, D. (1996). Control of RNA polymerase II elongation potential by a novel carboxyl-terminal domain kinase. J. Biol. Chem. 271, 27176-27183.

McDevitt, M. A., Fujiwara, Y., Shivdasani, R. A. and Orkin, S. (1997). An upstream, DNase I hypersensitive region of the hematopoietic-expressed transcription factor GATA1 gene confers developmental specificity in transgenic mice. Proc. Natl. Acad. Sci. USA 94, 7976-7981.

Medvinsky, A. and Dzierzak, E. (1996). Definitive hematopoiesis is autonomously initiated by the AGM region. Cell 86, 897-906.

Morcillo, P., Rosen, C., Baylies, M. K. and Dorsett, D. (1997). Chip, a widely expressed chromosomal protein required for segmentation and activity of a remote wing margin enhancer in Drosophila. Genes Dev. 11, 2729-2740.

Mukhopadhyay, M., Teufel, A., Yamashita, T., Agulnick, A. D., Chen, L., Downs, K. M., Schindler, A., Grinberg, A., Huang, S. P., Dorward, D. et al. (2003). Functional ablation of the mouse Ldb1 gene results in severe patterning defects during gastrulation. Development 130, 495-505.

Nasevicius, A. and Ekker, S. (2000). Effective targeted gene knockdown in zebrafish. Nat. Genet. 26, 216-220.

Nishioka, N., Nagano, S., Nakayama, R., Kiyonari, H., ljiri, T., Taniguchi, K., Shawlot, W., Hayashizaki, Y., Westphal, H., Behringer, R. R. et al. (2005). Ssdp1 regulates head morphogenesis of mouse embryos by activating the Lim1Ldb1 complex. Development 132, 2535-2546.

Onodera, K., Takahashi, S., Nishimura, S., Ohta, J., Motohashi, H., Yomogida, K., Hayashi, N., Engel, J. D. and Yamamoto, M. (1997). GATA1 transcription is controlled by distinct regulatory mechanisms during primitive and definitive erythropoiesis. Proc. Natl. Acad. Sci. USA 94, 4487-4492.

Ottersbach, K. and Dzierzak, E. (2005). The murine placenta contains hematopoietic stem cells within the vascular labyrinth region. Dev. Cell 8, 377387

Palstra, R. J., Tolhuis, B., Splinter, E., Nijmeijer, R., Grosveld, F. and de Laat, W. (2003). The beta-globin nuclear compartment in development and erythroid differentiation. Nat. Genet. 35, 190-194.

Patrinos, G. P., de Krom, M., de Boer, E., Langeveld, A., Imam, A. M., Strouboulis, J., de Laat, W. and Grosveld, F. (2004). Multiple interactions between regulatory regions are required to stabilize an active chromatin hub. Genes Dev. 18, 1495-1509.

Quinkertz, A. and Campos-Ortega, J. (1999). A new beta-globin gene from the zebrafish, betaE1, and its pattern of transcription during embryogenesis. Dev. Genes Evol. 209, 126-131. 
Ramain, P., Khechumian, R., Khechumian, K., Arbogast, N., Ackermann, C. and Heitzler, P. (2000). Interactions between chip and the achaete/scutedaughterless heterodimers are required for pannier-driven proneural patterning Mol. Cell 6, 781-790.

Robb, L., Lyons, I., Li, R., Hartley, L., Kontgen, F., Harvey, R. P., Metcalf, D. and Begley, C. G. (1995). Absence of yolk sac hematopoiesis from mice with a targeted disruption of the scl gene. Proc. Natl. Acad. Sci. USA 92, 7075-7079.

Rodriguez, P., Bonte, E., Krijgsveld, J., Kolodziej, K. E., Guyot, B., Heck, A. J., Vyas, P., de Boer, E., Grosveld, F. and Strouboulis, J. (2005). GATA1 forms distinct activating and repressive complexes in erythroid cells. EMBO J. 24, 23542366.

Schuh, A. H., Tipping, A. J., Clark, A. J., Hamlett, I., Guyot, B., Iborra, F. J., Rodriguez, P., Strouboulis, J., Enver, T., Vyas, P. et al. (2005). ETO-2 associates with $\mathrm{SCL}$ in erythroid cells and megakaryocytes and provides repressor functions in erythropoiesis. Mol. Cell. Biol. 25, 10235-10250.

Shivdasani, R. A., Mayer, E. L. and Orkin, S. H. (1995). Absence of blood formation in mice lacking the T-cell leukaemia oncoprotein tal-1/SCL. Nature 373, 432-434.

Shore, S. M., Byers, S. A., Maury, W. and Price, D. (2003). Identification of a novel isoform of Cdk9. Gene 307, 175-182.

Tolhuis, B., Palstra, R. J., Splinter, E., Grosveld, F. and de Laat, W. (2002) Looping and interaction between hypersensitive sites in the active beta-globin locus. Mol. Cell. Biol. 10, 1453-1465.

Torigoi, E., Bennani-Baiti, I. M., Rosen, C., Gonzalez, K., Morcillo, P., Ptashne, M. and Dorsett, D. (2000). Chip interacts with diverse homeodomain proteins and potentiates bicoid activity in vivo. Proc. Natl. Acad. Sci. USA 97, 2686-2691.

Tse, E., Smith, A. J., Hunt, S., Lavenir, I., Forster, A., Warren, A. J., Grutz, G., Foroni, L., Carlton, M. B., Colledge, W. H. et al. (2004). Null mutation of the Lmo4 gene or a combined null mutation of the Lmo1/Lmo3 genes causes perinatal lethality, and Lmo4 controls neural tube development in mice. Mol. Cell. Biol. 24, 2063-2073. van Meyel, D. J., Thomas, J. B. and Agulnick, A. (2003). Ssdp proteins bind to LIM-interacting co-factors and regulate the activity of LIM-homeodomain protein complexes in vivo. Development 130, 1915-1925

Wadman, I. A., Osada, H., Grutz, G. G., Agulnick, A. D., Westphal, H., Forster, A. and Rabbitts, T. (1997). The LIM-only protein Lmo2 is a bridging molecule assembling an erythroid, DNA-binding complex which includes the TAL1, E47, GATA1 and Ldb1/NLI proteins. EMBO J. 16, 31453157

Wang, J., Hoshino, T., Redner, R. L., Kajigaya, S. and Liu, J. (1998). ETO, fusion partner in $\mathrm{t}(8 ; 21)$ acute myeloid leukemia, represses transcription by interaction with the human N-CoR/mSin3/HDAC1 complex. Proc. Natl. Acad. Sci. USA 95, 10860-10865.

Warren, A. J., Colledge, W. H., Carlton, M. B., Evans, M. J., Smith, A. J. and Rabbitts, T. H. (1994). The oncogenic cysteine-rich LIM domain protein rbtn2 is essential for erythroid development. Cell 78, 45-57.

Westerfield, M. (1993). The Zebrafish Book: A Guide for the Laboratory Use of Zebrafish (Brachydanio rerio). Eugene, Oregon, USA: University of Oregon Press.

Whyatt, D. J., Karis, A., Harkes, I. C., Verkerk, A., Gillemans, N., Elefanty, A. G., Vairo, G., Ploemacher, R., Grosveld, F. and Philipsen, S. (1997). The level of the tissue-specific factor GATA1 affects the cell-cycle machinery. Genes Funct 1, 11-24.

Yoder, M. C., Hiatt, K., Dutt, P., Mukherjee, P., Bodine, D. M. and Orlic, D. (1997). Characterization of definitive lymphohematopoietic stem cells in the day 9 murine yolk sac. Immunity 7, 335-344.

Zhu, Y., Pe'ery, T., Peng, J., Ramanathan, Y., Marshall, N., Marshall, T., Amendt, B., Mathews, M. B. and Price, D. H. (1997). Transcription elongation factor P-TEFb is required for HIV-1 tat transactivation in vitro. Genes Dev. 11, 2622-2632.

Zhuang, Y., Cheng, P. and Weintraub, H. (1996). B-lymphocyte development is regulated by the combined dosage of three basic helix-loop-helix genes, E2A E2-2, and HEB. Mol. Cell. Biol. 16, 2898-2905. 